\title{
Active immunization using exotoxin A confers protection against Pseudomonas aeruginosa infection in a mouse burn model
} Ali Manafi ${ }^{1}$, Jamshid Kohanteb², Davood Mehrabani*3, Aziz Japoni4, Masoud Amini ${ }^{5}$, Mohsen Naghmachi ${ }^{6}$, Ahmad Hosseinzadeh Zaghi ${ }^{1}$ and Nazanin Khalili

Address: ${ }^{1}$ Department of Plastic Surgery, School of Medicine, Iran University of Medical Sciences, Tehran, Iran, ${ }^{2}$ Department of Medical Microbiology, School of Medicine, Shiraz University of Medical Sciences, Shiraz, Iran, ${ }^{3}$ Gastroenterohepatology Research Center, Nemazee Hospital, Shiraz University of Medical Sciences, Shiraz, Iran, ${ }^{4}$ Professor Alborzi Clinical Microbiology Research Center, Shiraz University of Medical Sciences, Shiraz, Iran, ${ }^{5}$ Department of Surgery, Shiraz University of Medical Sciences, Shiraz, Iran, ${ }^{6}$ Yasuj University of Medical Sciences, Yasuj, Iran and ${ }^{7}$ School of Pharmacy, Shiraz University of Medical Sciences, Shiraz, Iran

Email: Ali Manafi - dramanafi@yahoo.com; Jamshid Kohanteb - kohanj@sums.ac.ir; Davood Mehrabani* -mehrabad@sums.ac.ir; Aziz Japoni - japonia@hotmail.com; Masoud Amini - aminima@sums.ac.ir; Mohsen Naghmachi - grc@sums.ac.ir; Ahmad

Hosseinzadeh Zaghi - azizjaponi@gmail.com; Nazanin Khalili - khalilin@sums.ac.ir

* Corresponding author

Published: I February 2009

BMC Microbiology 2009, 9:23

This article is available from: http://www.biomedcentral.com/I47I-2/80/9/23

(C) 2009 Manafi et al; licensee BioMed Central Ltd.

This is an Open Access article distributed under the terms of the Creative Commons Attribution License (http://creativecommons.org/licenses/by/2.0), which permits unrestricted use, distribution, and reproduction in any medium, provided the original work is properly cited.
Received: 20 December 2007

Accepted: I February 2009

\begin{abstract}
Background: Pseudomonas aeruginosa is an important cause of nosocomial infection and may lead to septicemia and death. We evaluated the immunogenicity of semi-purified exotoxin A from the bacterium in a mouse burn model.

Methods: The toxoid was prepared from exotoxin $A$ taken from toxigenic strains of $P$. aeruginosa (PA 103). 50 mice were immunized with the toxoid, burned with hot metal and infected with I $\times$ $10^{8} \mathrm{CFU}$ of toxigenic strains of $P$. aeruginosa (experimental group); 25 non-immunized mice were also burned and infected (control group). The mortality rate and presence of any exotoxin and $P$. aeruginosa in the sera, liver and spleen were determined.

Results: In the experimental group, 2 mice died before the burns were administered and were excluded from the study. The remainder (48 mice) were challenged with a lethal dose of $P$. aeruginosa and followed for 70 days. 3 of these mice died. Neither P. aeruginosa nor exotoxin A was not detected in the liver, spleen or sera of the surviving mice. The protective efficacy of toxoid vaccination was therefore 93.8\%. In the control group, all mice died from bacteremia and septicemia, most (80\%) within 6 days, and $P$. aeruginosa and exotoxin A were isolated from sera, spleen and liver.
\end{abstract}

Conclusion: Active immunization of mice using a semi-purified exotoxin $A$ derived from $P$. aeruginosa was $93.8 \%$ effective at protecting mice from subsequent $P$. aeruginosa infections in a mouse burn model. 


\section{Background}

Pseudomonas aeruginosa is an opportunistic, non-fermentative, gram-negative rod which is an important cause of nosocomial infection leading to septicemia and death [1]. The mortality rate is higher than bacteremias caused by other gram-negative opportunistic pathogens. One of the most important features of the bacterium is its resistance to various antibacterial agents [2,3], and even newly developed antibiotics have failed to reduce the mortality rate associated with this organism [4].

There is increasing interest in bacterial virulence factors as a basis for effective vaccines and immunotherapies. Several extracellular products from $P$. aeruginosa such as exotoxin A, exoenzyme $S$, phospholipase and hemolysins have been studies as potential virulence factors [5]. The role of exotoxin A in the mortality of experimentallyinfected animals has been demonstrated [6] and the LD50 of the exotoxin reported to be $60-80 \mathrm{ng} / \mathrm{mouse}[7]$. Following a single injection of $80 \mathrm{ng}$ of exotoxin A, necrosis, and cellular swelling were detected in liver within $48 \mathrm{~h}$ [7]. Hemorrhage in the lungs and necrosis in the kidneys were also reported $[7,8]$. In eukaryotic cells, when exotoxin A turns into an activated enzyme, transfer of an adenosine diphosphate ribose moiety from NAD led to inactivation of elongation factor 2 and inhibition of protein synthesis [7]. Furthermore, the pre-existence of a high titer of anti-exotoxin A antibody reportedly increased the survival rate in patients with $P$. aeruginosa bacteremia [9].

This study was performed to determine the immunogenicity of a toxoid produced from exotoxin A of $P$. aeruginosa in a mouse burn model.

\section{Methods}

\section{Preparation of exotoxin A}

A toxigenic strain of $P$. aeruginosa (PA 103) was used for exotoxin A preparation. Exotoxin A was partially purified according to the method described by Pollack et al. [10] and Homma et al. [11]. P. aeruginosa was inoculated into tryptic soy agar and incubated at $37^{\circ} \mathrm{C}$ for $24 \mathrm{~h}$ in ambient conditions. The growth product of the slant cultures was inoculated into $500 \mathrm{~mL}$ of Muller-Hinton broth and incubated at $37^{\circ} \mathrm{C}$ for another $24 \mathrm{~h}$ in ambient conditions. The bacterial suspension was centrifuged for $30 \mathrm{~min}$ at $2000 \mathrm{~g}$ and the supernatant containing exotoxin A was sterilized by the Millipore filtration method $(0.45 \mu \mathrm{m})$ and concentrated $10 \times$ by polyethylene glycol (PEG) in a dialysis bag (30 mm diameter, Biogen, Mashhad, Iran). $200 \mathrm{~mL}$ of the concentrated supernatant was mixed with $200 \mathrm{~mL}$ of diethyl amino ethyl cellulose and stirred at $4{ }^{\circ} \mathrm{C}$. Exotoxin A was precipitated by the addition of 0.25 $\mathrm{M}$ of $\mathrm{NaCl}$ and $70 \%$ saturated ammonium sulfate. The precipitate was dissolved in $0.1 \mathrm{M}$ of Tris hydrochloride buffer containing $0.5 \mathrm{M}$ of $\mathrm{NaCl}$ and $0.02 \%$ of NaN3 (pH
8 at $4{ }^{\circ} \mathrm{C}$ ) and then applied into a column packed with Sephadex G75. The various fractions were collected and concentrated in dialysis bags (10 mm diameter, Biogen, Mashhad, Iran). Concentrated semi-purified exotoxin A was examined for presence of exotoxin A using the counter immunoelectrophoresis (CIEP) method. The protein content of exotoxin A was adjusted to $50 \mu \mathrm{g} / \mathrm{mL}$ by a spectrophotometer and used to immunize the mice.

\section{Animal selection}

75 white out-bred mice were provided from the Laboratory Animal Research Center of the Shiraz University of Medical Sciences, housed in an ambient temperature of $21 \pm 2{ }^{\circ} \mathrm{C}$ and relative humidity of $65-70 \%$, and given a balanced diet with free access to food and water. Animal selection, all experiments, subsequent care and the sacrifice procedure were all performed according to the guidelines and under the supervision of the Animal Care Committee of the Iran Veterinary Organization. The protocol for anesthesia, burn induction, post-burn care and sacrifice were identical for all animals. The animals were sacrificed under deep ether general anesthesia. All experiments were carried out under aseptic conditions. The study was approved by the Ethics Committee of the Shiraz University of Medical Sciences.

\section{Determination of LD50}

To determine the LD50 of the exotoxin, 50 additional mice were divided into 10 equal groups. A series of dilutions, up to ten-fold, of $50 \mu \mathrm{g} / \mathrm{mL}$ of semi-purified exotoxin A were prepared in PBS ( $\mathrm{pH} 7.2$ ). Each of the 10 groups was assigned to one of the 10 dilutions, and $1 \mathrm{~mL}$ of solution was injected intraperitoneally in each animal. Therefore, the mice received between 0.0005 and $5 \mu \mathrm{g}$ of exotoxin A. The mice were followed for 30 days. The LD50 was determined according to the Reed and Muench method [13] and calculated to be $0.5 \mu \mathrm{g}$.

\section{Preparation of toxoid}

To prepare the toxoid, $5 \mathrm{~mL}$ of semi-purified exotoxin A was mixed with $10 \mathrm{~mL}$ of PBS, $\mathrm{pH} 7.2$, containing $0.01 \mathrm{M}$ sodium phosphate, $0.15 \mathrm{M}$ sodium chloride and $4 \%$ formaldehyde, and incubated at $37^{\circ} \mathrm{C}$ for 4 days before being dialyzed against phosphate buffer for $48 \mathrm{~h}$. The attenuated toxin was sterilized by Millipore filtration $(0.45 \mu \mathrm{m})$.

\section{Mice immunization with toxoid}

50 mice were assigned to the experimental group. 2 mice died before the burns were administered and were not enrolled in the study. The remaining 48 mice were immunized with the toxoid. Each mouse received weekly subcutaneous injections for 6 weeks. Each injection contained $100 \mu \mathrm{g}$ of semi-purified toxoid in $2 \mathrm{~mL}$ of PBS. 1 week after the last injection, the animals were bled from the eye 
and the samples checked for the presence of antitoxin using CIEP. To determine more precisely the ranges of immunity in the vaccinated mice, the titer of anti-exotoxin A was measured by enzyme-linked immunosorbent assay (ELISA) as previously described [14].

\section{Rabbits hyperimmunization with toxoid}

A group of 4 rabbits were immunized with the toxoid. Each rabbit received weekly subcutaneous injections for 6 weeks. Each injection contained $200 \mu \mathrm{g}$ of semi-purified toxoid in $4 \mathrm{~mL}$ of PBS. 1 week after the last injection, the animals were bled from the ear. Sera were pooled and the presence of antitoxin against $P$. aeruginosa confirmed by CIEP. The sera were used as an antitoxin when necessary, to evaluate the presence of the toxin in the sera of the experimental and control mice.

\section{Counterimmunoelectrophoresis}

CIEP was carried out for qualitative detection of toxin and antitoxin in the sera of the immunized mice [12]. This technique was applied on $13 \times 18 \mathrm{~cm}$ glass slides which were covered by $1 \%$ melted agarose in acetate buffer $(\mathrm{pH}$ 7.6). 2 rows of wells with a diameter of $6 \times 6 \mathrm{~mm}$ were punched in each glass slide and $0.4 \mathrm{~mL}$ of semi-purified exotoxin A or serum containing the exotoxin A (antigen) and $0.4 \mathrm{~mL}$ of immunized mice or rabbit serum (antibody) were placed in the anodal and cathodal wells, respectively. The slide was subjected to electrophoresis using an acetate buffer (pH 7.6 at $40 \mathrm{~mA}$ for $30 \mathrm{~min}$ ). Production of a precipitation line between the two wells indicated the presence of antitoxin or toxin A in the sera. The Amidoblack staining method was used to reveal the precipitation lines more clearly.

\section{Determining the efficacy of the candidate vaccine}

73 mice $(48$ immunized = experimental group, 25 nonimmunized $=$ control group) were anesthetized and burns (grade 3 ) were induced on the thigh using a $1 \times 2 \mathrm{~cm}$ piece of hot metal, producing a burn of up to $10 \%$ of the total body surface and extending to all layers of skin but not involving the muscular tissue. After $24 \mathrm{~h}, 10^{8}$ colony forming units (CFU) of toxigenic strains of $P$. aeruginosa (PA 103) were inoculated subcutaneously into the burned area.

Both groups were supervised in their cages for 70 days. Samples were obtained from the infected areas using sterile swabs and saline and checked for the presence of $P$. aeruginosa at different time intervals. Blood samples and the tissue samples of spleens and livers of dead mice were also examined for presence of $P$. aeruginosa. The presence of $P$. aeruginosa was determined as $\mathrm{CFU} / \mathrm{mL}$ of the blood samples. The quantity of $P$. aeruginosa in the spleens and livers was measured as the number of CFU per $1 \mathrm{~g}$ of homogenized tissue. The survival rate in both groups was com- pared. The efficacy of vaccine was calculated as the percentage survival during the 70-day observation period following inoculation with toxogenic $P$. aeruginosa (PA 103).

\section{Confirmation of infection}

Using sterile swabs and saline, samples were obtained from the infected burns. The swabs were cultured on blood and Muller-Hinton agar plates and incubated at $37^{\circ} \mathrm{C}$ under ambient conditions for $24 \mathrm{~h}$. P. aeruginosa was diagnosed by colony morphology, a zone of hemolysis and oxidase, methyl red, Voges Proskauer, citrate and TSI tests [15].

\section{Results and discussion}

Mice immunized with a semi-purified exotoxin A from $P$. aeruginosa $(\mathrm{n}=48)$ and non-immunized mice $(\mathrm{n}=25)$ received full-thickness burns to the skin of the thigh and were then challenged with $10^{8} \mathrm{CFU}$ of $P$. aeruginosa (a lethal dose). They were followed for 70 days. Antitoxin and exotoxin A were detected in the sera of the experimental group by CIEP. The antibody titer ranged from 1:16 to 1:512 in the immunized mice using ELISA (Table 1).

During the follow-up period, 3 mice $(6.3 \%)$ in the experimental group died. All non-immunized mice developed septicemia and died within 3 weeks of inoculation with $P$. aeruginosa. In serial wound swabs (diluted in $1 \mathrm{ml}$ of distilled water) from the immunized mice, $1.5 \times 10^{8} \mathrm{CFU} / \mathrm{mL}$ of $P$. aeruginosa were detected 1 day after wound inoculation and levels decreased to 0 over 2 weeks. In the nonimmunized mice, the colony count increased for 6 days post-inoculation with $P$. aeruginosa and the majority of the mice $(80 \%)$ died within this period. Table 2 shows the colony count, survival rate and results of cultures of the blood, spleen and liver of the non-immunized mice. The blood cultures of $8 \%, 32 \%, 32 \%$ and $12 \%$ of the nonimmunized mice were positive after 2, 3, 4 and 6 days post-inoculation, respectively. The spleen and liver cultures were positive in $76 \%$ of the mice who died within 6 days of inoculation. Exotoxin A was detected in their sera 2 days post-infection and remained detectable for 6 days.

Table 3 shows the colony count, survival rate, quantity of exotoxin and anti-exotoxin $\mathrm{A}$ and the result of cultures of

Table I: Antitoxin titer of immunized mice using ELISA

\begin{tabular}{cc}
\hline Antitoxin titer & No. (\%) \\
\hline $1: 16$ & $2(4.5)$ \\
$1: 32$ & $8(17.8)$ \\
$1: 64$ & $10(22.2)$ \\
$1: 128$ & $15(33.3)$ \\
$1: 256$ & $5(11.1)$ \\
$1: 512$ & $5(11.1)$
\end{tabular}


Table 2: Survival rates, presence of exotoxin A, culture results and colony counts in the control group (non-immunized mice) inoculated with $P$. aeruginosa

\begin{tabular}{|c|c|c|c|c|c|c|}
\hline \multirow{2}{*}{$\begin{array}{c}\text { Post-inoculation time } \\
\text { (day) }\end{array}$} & \multirow{2}{*}{$\begin{array}{c}\text { Number of animals alive } \\
\text { (survival rate, \%) }\end{array}$} & \multirow{2}{*}{$\begin{array}{c}\text { CFU/mL from inoculated } \\
\text { burns }\end{array}$} & \multirow[t]{2}{*}{ Exotoxin A in sera (\%)* } & \multicolumn{3}{|c|}{ Positive culture (\%) } \\
\hline & & & & Liver & Spleen & Blood \\
\hline 1 & $25(100)$ & $1 \times 10^{8}$ & - & - & - & - \\
\hline 2 & $25(100)$ & $1.14 \times 10^{8}$ & $2(8)$ & - & - & $2(8)$ \\
\hline 3 & $12(48)$ & $1.25 \times 10^{8}$ & $8(32)$ & $2(8)$ & $2(8)$ & $8(32)$ \\
\hline 4 & $8(32)$ & $1.6 \times 10^{8}$ & $8(32)$ & $8(32)$ & $8(32)$ & $8(32)$ \\
\hline 6 & $5(20)$ & $1.7 \times 10^{8}$ & $3(12)$ & $5(20)$ & $5(20)$ & $3(12)$ \\
\hline
\end{tabular}

* detected with CIEP

the blood, spleen and liver of the mice in the experimental group. As expected, no exotoxin A was detected in the sera by CIEP, which may be due to neutralization of the toxin by previously antitoxins formed following immunization. Bacterial infection is a major complication after thermal injury, especially in developing countries [16-18]. 75\% of deaths following burns are related to microbial infections [19]. P. aeruginosa is a frequently isolated bacterium that causes septicemia and death [17]. It is a ubiquitous opportunistic, non-fermenting, gram-negative rod that can infect patients with impaired immune systems. Treatment of $P$. aeruginosa infection is frequently hindered by antibiotic resistance, and multi-drug resistant strains are mostly isolated from burn wound infections $[3,4,20]$. An efficient vaccine is therefore needed. After colonizing the site of the burn, $P$. aeruginosa produces several virulence factors, such as exotoxin $\mathrm{A}$, alkaline protease and elastase, which affect the host tissue. High titers of antitoxin against exotoxin A in patients infected with $P$. aeruginosa reduces the risk septicemia and death $[9,21]$.

\section{Conclusion}

Exotoxin $\mathrm{A}$ is the principal lethal factor of $P$. aeruginosa. It seems logical that a toxoid of exotoxin A could be used as an effective vaccine. Our study shows that in mice immunized with semi-purified exotoxin $\mathrm{A}$, a protective titer of antitoxin developed that effectively prevented the experimentally infected animals from septicemia and death. The majority $(93.8 \%)$ of immunized infected mice survived during 70 days of observation after a burn wound was inoculated with $P$. aeruginosa while all the non-immunized mice in the control group died. The rising antibody titer in the surviving mice and the decrease in the mortality rate indicate the presence of an effective antitoxin in the immunized mice.

Pavlovskis et al. [22] found that the survival rate did not increase significantly following active immunization with a toxoid of exotoxin A and infection with $P$. aeruginosa in burned mice. However, Matsumato et al. [5] found that immunization with a combination of alkaline protease and toxoid of exotoxin A decreased mortality. Some investigators have reported that active immunization with a lipopolysaccharide and an outer membrane protein (OMP) of $P$. aeruginosa could control the infection in the burned area $[23,24]$. Our study, using a semi-purified exotoxin A that contained trace amounts of LPS and OMP, points to a higher efficacy than a toxoid prepared from purified exotoxin A. Our study did not include different strains of the bacterium but our results can be used for further studies on the purification of, and determination of cross-immunization of, different strains of the bacterium [25].

Three of the immunized mice $(6.3 \%)$ died. This may be due to the presence of invasive factors other than exotoxin

Table 3: Survival rates, presence of exotoxin A, culture results and colony counts in the experimental group (immunized mice) inoculated with $P$. aeruginosa

\begin{tabular}{|c|c|c|c|c|c|c|c|}
\hline \multirow[t]{2}{*}{$\begin{array}{l}\text { Post-inoculation } \\
\text { time (day) }\end{array}$} & \multirow[t]{2}{*}{$\begin{array}{c}\text { Number of } \\
\text { animals alive } \\
\text { (survival rate, \%) }\end{array}$} & \multirow[t]{2}{*}{$\begin{array}{c}\text { CFU/mL from } \\
\text { inoculated } \\
\text { burns }\end{array}$} & \multirow[t]{2}{*}{$\begin{array}{c}\text { Exotoxin A } \\
\text { in sera } \\
(\%)^{*}\end{array}$} & \multirow[t]{2}{*}{$\begin{array}{c}\text { Positive } \\
\text { culture } \\
\text { (\%) }\end{array}$} & \multicolumn{3}{|c|}{$\begin{array}{c}\text { Number of } \\
\text { animals alive } \\
\text { (survival rate, \%) }\end{array}$} \\
\hline & & & & & Liver & Spleen & Blood \\
\hline I & $48(100)$ & $1.5 \times 10^{8}$ & ND & $48(100)$ & - & - & - \\
\hline 4 & $48(100)$ & $1.4 \times 10^{7}$ & ND & $48(100)$ & - & - & - \\
\hline 7 & 47 (98) & $1.3 \times 10^{6}$ & ND & $47(100)$ & I (2) & I (2) & I (2) \\
\hline 11 & $46(96)$ & $1.2 \times 10^{5}$ & ND & $47(98)$ & $I(2)$ & $1(2)$ & I (2) \\
\hline 14 & $45(94)$ & $1 \times 10^{4}$ & ND & $45(94)$ & $I(2)$ & $1(2)$ & $1(2)$ \\
\hline
\end{tabular}

ND, not detectable by CIEP; * neutralizing antibody detected 
A, such as elastase, alkaline protease, hemolysins, leukocidin, siderophores, siderophore uptake systems and pyocyanin diffusible pigment. Passive immunization was not evaluated in this study: We chose to study active immunization because this could play a role in high-risk occupations such as fire fighting and baking. Our results demonstrate that in a mouse model of bacterial infection in burn wounds, active immunization with semipurified exotoxin A protected against infection with $P$. aeruginosa and reduced mortality.

\section{Authors' contributions}

AM plastic surgeon, main researcher, cooperated in inducing burns. JK microbiologist, immunological methods. DM laboratory animal design, manuscript draft provision. AJ microbiologist, bacteriological methods. MA general surgeon, cooperated in inducing burns. $\mathrm{MN}$ assistant in bacteriological methods. AHZ assistant surgeon and laboratory animal carer. NK assistant in immunological methods

\section{Acknowledgements}

The authors would like to thank the Office of the Vice Chancellor for Researches of the Shiraz University of Medical Sciences, Iran, the University of Medical Sciences, and the Razi Vaccine and Serum Research Institute for financial support; the Laboratory Animal Research Center of the Shiraz University of Medical Sciences for providing laboratory animals; and Ghotbeddin Burn Hospital for their cooperation.

\section{References}

I. Pollack M: Principles and practice of infectious diseases. In Pseudomonas aeruginosa 5th edition. Edited by: Mandell GL, BennettjeDolin R. Philadelphia, PA: Churchill Livingstone; 2000:2310.

2. Chonghua LI, Nicolau DP, Lister PD, Quintiliani R, Nightingale $\mathrm{CH}$ : Pharmacodynamic study of B-lactamase alone and in combination with B-lactamase inhibitors against Pseudomonas aeruginosa processing an inducible b-lactamase. I Antimicrobiol Chemother 2004, 53:297-304.

3. Japoni A, Alborzi A, Kalani M, Nasiri J, Hayati M, Farshad S: Susceptibility patterns and cross-resistance of antibiotics against Pseudomonas aeruginosa isolated from burn patients in the south of Iran. Burns 2005, 32:343-347.

4. Ishil Y, Alba J, Kimura S, Shiroto K, Yamaguchi K: Evaluation of antimicrobial activity of B-lactam antibiotics using $E$ test against clinical isolates from $\mathbf{6 0}$ medical centers in Japan. Inter J Antimicrobial Agents 2005, 25:296-301.

5. Motsumoto T, Tateda K, Furuya N, Miyazaki S, Ohno A, Ishii $Y$, Hirakata $Y$, Yamaguchi K: Efficacies of alkaline protease, elastase and exotoxin $A$ toxoid vaccines against gut-derived Pseudomonas aeruginosa sepsis in mice. J Med Microbiol 1998, 47(4):303-308.

6. El-Zaim HS, Chopra AK, Peterson JW, Vasil ML, Heggers JP: Protection against exotoxin A (ETA) and Pseudomonas aeruginosa infection in mice with ETA-specific antipeptide antibodies. Infect Immun 1998, 66:555I-4.

7. Armstrong S, Yate SP, Merrill AR: Insight into the catalytic mechanism of $P$. aeruginosa exotoxin A strains of toxin interaction with eukaryotic elongation factor. NZ J Biol Chem 2002, 29:227.

8. Wretfind B, Pavlovskis OR: The role of protease and exotoxin A in the pathogenecity of Pseudomonas aeruginosa infections. Scand J Infect Bis Suppl 198I, 29:13-19.

9. Pollack M, Callahan LT, Taylor NS: Neutralizing antibody to Pseudomonas aeruginosa exotoxin in human serum: evidence for in vivo toxin production during infection. Infect Immun 1976, 1 4:942-947.
10. Pollack M, Prescott RK: Toxoid from exotoxin A of $P$. aeruginosa. Preparation and characterization. J Infect Dis 1982, 145:688-98.

II. Homma JY, Tanimoto $\mathrm{H}$ : A multicomponent $\boldsymbol{P}$. aeruginosa vaccine consisting of toxoid of protease, elastase, exotoxin $A$ and a common protective antigen (OEP). Application in patients with diffuse panbronchiolitis. Antibiotic Chemother 1987, 39:215-221.

12. Kohanteb J, Ardehali S: Cross reaction of sera forms patients with various infectious diseases with Leishmania infantum. Med Principles Practice 2005, 14:79-82.

13. Reed L, Muench HA: Simple method for estimating $\mathbf{5 0 \%}$ end point. Am J Hyg 1938, 25:493-497.

14. Elzaim HS, Chopra AK, Peterson JW, Goodheart R, Heggers JP: Generation of neutralizing antipeptide antibodies to the enzymatic domain of Pseudomonas aeruginosa exotoxin A. Infect Immun 1998, 66:2170-79.

15. Forbes BA, Sahm DF, Weissfeld AS: Pseudomonas, Burkholderia and similar organisms. Baily and Scott's Diagnostic Microbiology 1998:448-46I.

16. Saadat M: Epidemiology and mortality of hospitalized burn patients in Kohkiluye and Boyerahmad Province (Iran): 2002-2004. Burns 2005, 31:306-309.

17. Bang R, Sharma PNM, Sanyal SC, Al-najjadah I: Septicemia after burn injury: a comparative study. Burns 2002, 78:746-75I.

18. Karimi-estahbanati H, Pourkashanif P, Ghanaatpishe H: Frequency of Pseudomonas aeruginosa serotypes in burn wound infections and their resistance to antibiotics. Burns 2002, 28:340-48.

19. Donati L, Scammazo F, Gervasoni M, Maglian A, Stankow B: Infection and antibiotic therapy in $\mathbf{4 0 0 0}$ burned patients in Milan, Italy between 1976 and 1988. Burns 1993, 4:345-8.

20. Agnihotri N, Gapata V, Joshi RM: Aerobic bacterial isolates from burn wound infections and their antibiograms: a five-year study. Burns 2004, 30:24I-243.

21. Pavlovskis OR, Pollack M, Callahan LT 3rd, Iglewski BH: Passive protection by antitoxin in experimental Pseudomonas aeruginosa burn infections. Infect Immun 1977, 18:596-602.

22. Pavlovskis OR, Edman DC, Lepply SH, Wretlind B, Lewis LR, Martin KE: Protection against experimental Pseudomonas aerugionsa infection in mice by active immunization with exotoxin $A$ toxoid. Infect Immun I 98I, 32:68I-689.

23. Cryz SJ, Furer E, Germanier R: Protection against fatal Pseudomonas aeruginosa burn wound sepsis by immunization with lipopolysaccharide and high molecular weight polysaccharide. Infect Immun 1984, 43(3):795-799.

24. Vonspecht B, Hungerer K, Lucking C, Schmitt A, Domdey H: Outer membrane proteins of Pseudomonas aeruginosa as a vaccine candidates. J Biotech 1996, 44: I45-I53.

25. Japoni A, Farshad S, Alborzi A, Kalani M, Mohamadzadegan R: Comparison of arbitrarily primed-polymerase chain reaction and plasmid profiles typing of Pseudomonas aeruginosa strains from burn patients and hospital environment. Saudi Med J 2007, 28(6):899-903.

Publish with Bio Med Central and every scientist can read your work free of charge

"BioMed Central will be the most significant development for disseminating the results of biomedical research in our lifetime. "

Sir Paul Nurse, Cancer Research UK

Your research papers will be:

- available free of charge to the entire biomedical community

- peer reviewed and published immediately upon acceptance

- cited in PubMed and archived on PubMed Central

- yours - you keep the copyright 